\title{
Technological literacy reconsidered: a model for enactment
}

\author{
Åke Ingerman • Brandon Collier-Reed
}

Published online: 23 January 2010

(C) The Author(s) 2010. This article is published with open access at Springerlink.com

\begin{abstract}
This paper presents a model to describe technological literacy as enacted by indiviudals in the course of shaping their lives and the world around them. The model has two interrelated facets - the potential for and enactment of technological literacy-where enactment and potential mutually constitute each other. This potential is made up of knowledge of a particular situation, personal engagement with a situation, and social engagement in the world. Enactment requires a particular set of competencies in action, which together helps shape the situation: recognizing needs; articulating problems; contributing towards the technological process; and analysing consequences. The implications of this model for technological literacy in the context of the individual and society, and the role of technology education in developing technological literacy, are discussed.
\end{abstract}

Keywords Technological literacy · Technology education

\section{Introduction}

Technological literacy has emerged as a central focus in the discussions on the outcomes of technology education (Dugger 2008; Frank 2005; Rose 2007; Waetjen 1993; Young et al. 2002) as effort is directed towards equipping people to participate in an increasingly technological world. When technological literacy was first employed as a descriptor in the 1970s, it was viewed as something that 'embodied the knowledge and skills needed to function in a society dominated by technological innovation' (Rose 2007, p. 35). Many views have emerged since then on what it means to be technologically literate (cf. Barnett 1995; de Vries 2005; Devon and Ollis 2007; Gagel 1997; Hayden 1989; Kahn and Kellner

\footnotetext{
Å. Ingerman $(\bowtie)$

Department of Education, University of Gothenburg, Göteborg, Sweden

e-mail: ake.ingerman@gu.se

B. Collier-Reed

Centre for Research in Engingeering Education \& Department of Mechanical Engineering,

University of Cape Town, Cape Town, South Africa

e-mail: Brandon.Collier-Reed@uct.ac.za
} 
2005; Waetjen 1993). For example, the National Academy of Engineering (NAE) have published Technically Speaking (Pearson et al. 2002) where they describe technological literacy as encompassing 'three interdependent dimensions-knowledge, ways of thinking and acting, and capabilities' (p. 3). Another popular definition has been developed by the International Technology Education Association (ITEA) as part of their Technology for All Americans Project (TfAAP). Here, technological literacy is taken as being able to think about technological issues from various perspectives and to be able to appreciate the 'interrelationships between technology and individuals, society, and the environment' (TfAAP and ITEA 1996, p. 11). The ITEA (2000/2002/2007), having defined technological literacy as the ability to 'use, manage, assess, and understand technology' (p. 9), have gone as far as developing a series of standards that spell out in detail how to achieve technological literacy and what goals need to be achieved at different grades within a school curriculum.

It is clear from these definitions that being technologically literate can, on the individual level, for example, help consumers make better-informed decisions, while on a societal level, decisions on global issues that affect the environment, for instance genetic engineering, can be discussed and debated from a position of understanding. Furthermore, being technologically literate can ensure an individual's opinions and decisions are well informed and developed from a sound knowledge base. Rose (2007), who interviewed 13 leaders of professional organisations representing science, engineering and mathematics communities, found that the dominant view of what made for a technologically literate person was one who 'understands linkages among the individual, technology, environment, and society' (p. 42). However, what it is that is required in order to be considered technologically literate remains difficult to articulate as there is no one universal set of requirements that satisfies technological 'literateness'. What persons need to be would vary depending on the socio-cultural context in which they found themselves. For example, a technologically literate inhabitant of a tribe in Papua New Guinea would have very different characteristics to a technologically literate inhabitant of Sydney in Australia. Thus, we must understand technological literacy in relationship to situations rather than simply in terms of generic characteristics.

In our previous work, we posit that for a person to be considered technologically literate, they must 'understand nature of technology, have a hands-on capability and capacity to interact with technological artefacts, and ... be able to think critically about issues relating to technology' (Collier-Reed 2008, p. 24). A specific aspect that we wish to highlight here is the notion of action. We argue that 'doing' holds a central position in all aspects relating to both technology and technological literacy. Hayden (1989) is another who specifically highlights action as an important component of technological literacy when he refers to the need to be able to 'select, properly apply, then monitor and evaluate appropriate technologies' (p. 231-emphasis added) in a given situation. In this way, technological literacy in a situation is constituted through actions.

Dakers (2006) argues in the book Defining Technological Literacy that '[w]e need to develop a new language, a new literacy, in order to both understand our brave new world, and learn how to live a meaningful existence in it' (p. 1). Seen in this way, technological literacy is about how we live our lives. It would appear from the framework for technological literacy presented in Dakers (2006) that this 'new literacy' remains located firmly within technology. For example, Feenberg (2006) explores the origins of technology from the Greek Techne and maps out alternative theories on the progress and control of technology, De Vries (2006) has taken as his starting point an analysis of the nature of technological artefacts and thereafter defines technological knowledge in terms of the 
nature of artefacts and their interaction with other physical objects, and Michael (2006) introduces a sociological perspective on the use of technological artefacts where he analyses the sociological consequences of the use of technology and advocates developing the forms in which citizens can voice their views on technology. This view of technological literacy as being dialectically intertwined with technology per se is not unique to this book, and can be found throughout the literature-evidenced, for example, in the definitions presented from the ITEA and NAE earlier. Furthermore, the distinction between an intra-disciplinary idea of technological literacy and a 'citizenship' idea is analougous to a similar discussion regarding scientific literacy as articulated by Roberts (2007).

We characterise many of the the current main-stream descriptions of technological literacy as mostly involving the 'content' of technological literacy. This is typified by the subtitle of the ITEA's Standards for Technological Literacy, where the standards are specifically referred to as 'Content for the study of technology' (ITEA 2000/2002/2007, cover). Complementary to the content of technological literacy, is the idea of the function of technological literacy, which would appear to be less clearly articulated in the literature. We suggest that the function of technological literacy - 'the mode of action by which [technological literacy] fulfils its purpose' (Simpson et al. 1989, p. 263)—is important to articulate with respect to both individuals and society. In relation to the function of technological literacy, we will focus our attention on 'the mode of action', rather than on the purpose. In the model we will develop below, we place emphasis on the interrelationship between content and function for technological literacy in a particular situation. Technological literacy is thus something that is taking place-something that is realised in particular settings and situations-over and over again. In this situation, there is certain content to what technological literacy means and the technological literacy has a function in what is taking place.

\section{Being technologically literate}

At this stage, it is necessary to ask the question: Why should an individual aspire to be technologically literate? It is common cause that technology in its various forms concerns everybody. However, Waetjen (1993) has argued that 'people can, and do, live without the faintest notion of the nature of technology' (p. 5). This is highlighted by two Gallup surveys undertaken to assess what North Americans think about technology (Rose and Dugger 2002; Rose et al. 2004) where more than two-thirds (68\%) of respondents indicated that the first thing that came to mind when they heard the word technology was computers. The next highest response was electronics at 5\%. For people who see technology in this way, technology typically takes a narrow form-such as information technology (experienced as computers) - to the extent that for them, 'technology equates with computers and ... [hence] technological literacy with "computer literacy" (Barnett 1995, p. 120). For many others, however, the impact that technology has on their lives is something that they negotiate on a daily basis.

In trying to make sense of what it means to be literate in this context, there is a growing view that it is reasonable to '[substitute] 'literacy' for 'competence'" (Barnett 1995, p. 120). We do not support this view, but rather argue that a definition of technological literacy must relate to the context of the negotiation described above, i.e. the function that technological literacy has embedded in this particular negotiation. Technological literacy would, in such situations, point to certain ways of dealing with that negotiation, by taking into account the nature of technology as well as aspects of technology that we argue relate 
to certain kinds of content. Furthermore, technological literacy must exist in the relation between a subject and an object, i.e. between an individual and technology in its broadest sense. Hence, it is neither about the individual as such, nor is it about technology as such, but about how individuals deal with aspects of their lives in a way which relates to technological artefacts and processes.

We would suggest that there are two aspects missing from the broader discussion around technological literacy presented above. Firstly, technological literacy is, in its essence, something that is enacted by individuals with respect to technology and is a part of the way in which we shape the world. Technological literacy is not primarily a characteristic of an individual, but a characteristic of how individuals experience and act in relation to situations and technological processes. Technological literacy is thus relational, and we cannot talk about an individual as being technologically literate without considering what processes we see their experiences and acts in relation to, nor can we talk about processes as embodying technological literacy without considering the individuals involved, and their acts and experience. In a sense, we describe technological literacy as an aspect of learning and living, where learning and living are seen in a relational perspective, similar to, for example, the phenomenographic view of learning (Marton and Booth 1997).

The second aspect we feel is missing from the discussion around technological literacy is that, whilst still maintaining a focus on the individual, we would like to add a consideration of technological literacy on the level of society as a collective, or as constituted by sets of collectives. As an example, it is quite clear that in a construction environment, there will be numerous interactions between different groups of experts-each with different competencies.

\section{A model for enactment as realisation for the potential of technological literacy}

To explore the meanings of technological literacy we are proposing a model with two interrelated facets: the potential for technological literacy as the first and the enactment of technological literacy as the second (see Fig. 1). We argue that enactment and potential mutually constitute each other. At a particular point in the process, individuals can experience a number of potentials in the situation in relation to knowledge, personal and social engagement. The enactment, in turn, changes the situation in such a way that new potentials are able to be constituted.

Drawing on our argument above, the content of technological literacy is primarily related to what we refer to here as the potential for technological literacy (and to a lesser extent, the enactment aspect). Similarly, the function of technological literacy is primarily related to the enactment of technological literacy (and to a lesser extent, the potential). We will expand on this model below. It is important to bear in mind that that we are analysing technological literacy-potential and enactment-with respect to a particular situation, even though that situation may be multi-layered in terms of scope, interest, and concurrent processes.

Potential for technological literacy

\section{Knowledge}

Something that has been widely discussed in the emergence of the notion of technological literacy is what it means to have knowledge of a particular situation (cf. Hayden 1989, 


\section{Situation}

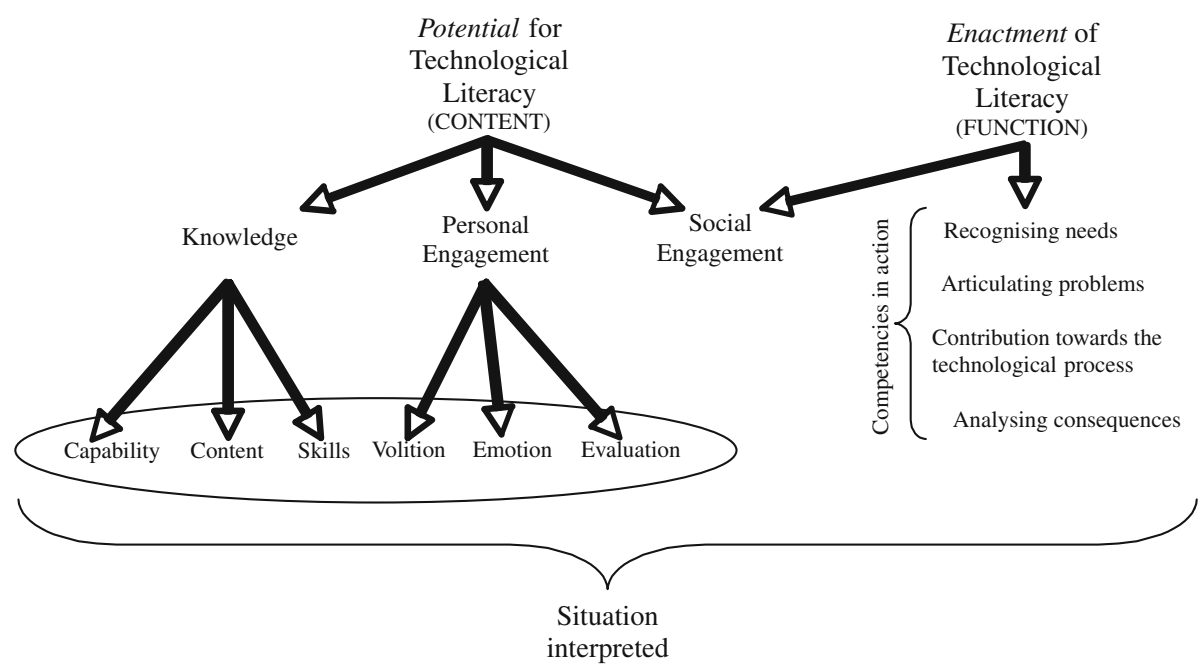

Fig. 1 An analysis of technological literacy with respect to a particular situation

p. 228; Young et al. 2002, p. 76). There are several aspects to knowledge, some of which have been suggested as capability, skills and the content of particular ways of approaching the environment you find yourself in-given the expectations of the situation. Capability refers directly to the potential for interaction with technology, and hence interaction with the nature of technology. Similarly, Levande (2003), p. 88) has argued that 'capability is application, the use of technological knowledge'. Capability implies a competence to be able to deal with a multi-faceted situation, as well as an ability to structure relevant and irrelevant aspects of the situation in terms of technological importance. Capability connects to a number of skills, which may or may not be applied in the particular situation, and an inherent ability to use these skills. Young et al. (2002), for example, refer to the requirement of society to 'possess a range of ... skills in using everyday technologies' (p. 76). Interwoven within both skills and capability is a reliance on content. Waetjen (1993) cautions us at this point that technology education does not yet have a 'structured domain of knowledge' (p. 8).

\section{Personal engagement}

Personal engagement as we will use it refers, on the one hand, to the rationale for engaging in a situation in a particular way-and relies thus on evaluation (cf. Steffens 1986, as cited in Waetjen 1993) arguing that technological literacy involves evaluation skills) and volition, for example, in terms of purpose. Furthermore, personal engagement refers to volition in terms of ethical considerations in the situation and to the emotional basis in which instinctive reactions to the situation manifest themselves. We argue that evaluation, volition, and emotion are what guides individuals in the application of capability, content and skills. They work together as lenses through which the situation is interpreted and give rise to alternative ways of action-as well as a basis for discrimination between them. 


\section{Social engagement}

In shaping our world, we interact with it physically. However, a very small part of the application of technological knowledge and personal engagement is performed by an individual in isolation with respect to society. Instead we are immersed in a society of interactions through and around technology. It is through social engagement-for example, through participation in specific practices-in society that the potential for technological literacy as we discuss above can be manifested. In this way, we argue that social engagement both encompasses social interaction between humans and what is traditionally portrayed as physical interaction with the world. Our argument is that the realisation of technology in a society occurs through processes that include interaction between different individuals (who may assume different roles) and the application of various tools (which have been pre-produced and have a well defined application). Kahn and Kellner (2005) support this view by arguing that "literacy' is not a singular set of abilities but is multiple and comprises gaining competencies involved in effectively using socially constructed forms of communication and representation' (p. 240).

Social engagement is essential for access to, for example, knowledge, tools and support. Social engagement is what frames the realisation of potential, and in that framing, what gives access to processes that can be regarded as embodying technological literacy. With social engagement, we thus point to the competence needed to take one's place in a certain domain as well as others allowing that person to be a part of that domain-and to then take up a role that they can manage with their capability. An example of this idea would be the notion of work-sharing in a community of practice. Wenger (1998) describes participation in this community of practice as referring to 'a process of taking part and also to the relations with others that reflect this process. It suggests both action and connection' (p. 55).

\section{Enactment of technological literacy}

The enactment of technological literacy is how knowledge and personal engagement are put into 'action' in the world through social engagement. This enactment requires a particular set of competencies in action, which together helps shape the situation: recognizing needs; articulating problems; contributing towards the technological process; and analysing consequences. These will be discussed in turn below.

If you do not recognise need, you cannot participate in the technological process. We argue that in every particular situation, needs are reconstituted. This is highlighted by means of the following example: Imagine that you are sitting watching television at home and suddenly feel thirsty. Most likely, your reaction will be to fetch a glass, turn on a tap and then sit down again to enjoy your refreshing cold water-free from germs, dirt and other worrying problems. In this situation, you have (probably unconsciously) reconstituted your need for liquid, and articulated this as the problem of making use of the infrastructure present in your home. All this changes the minute your water pipe burstsyour focus is then on the system that provides the water (taken for granted in the first instance) and not on the water per se. On the other hand, the reason your water pipes are there in the first place, is because the need of water is recurrent in many aspects of life.

It is thus through the articulation of problems that the level of technological literacy becomes apparent. One immediate aspect of the quality of the enactment of technological literacy is the relationship between the articulated problem and the need identified-in other words, in what ways will the solution of the problem satisfy the need? Correspondingly, the 
level of technological literacy in the technological process will also be framed by the articulated problem, since that is what the process will be aimed towards.

Contributing towards the technological process is very much about realizing potential from knowledge and personal engagement-in an environment of interacting with others and the world in the situation through social engagement. This is often manifested through some sort of design process. Similarly, each contribution moves the process along one of the multiply available paths towards possible solutions to problems. Being able to elect not to enact all that you have the potential to enact in a particular situation is a further sign that not everything needs to be considered in every part of every process. We might say that in the practice of technology, there are always black boxes that we locally take for granted. In the example of quenching your thirst above, the water reticulation system is typically such an instance of a black box-you do not think about it very much when it is there, even though you could.

Analysing consequences forms an important part of the feedback loop that shapes the final output of a technological process in question. It may be essential, for example, to change the strategy of skills employed, or the raw material used. A 'professional' has the ability to anticipate the result of a process before it occurs, and feed that result back into the decision making process. This then corresponds with the potential for evaluation. We see the analysing of consequences primarily on three levels: functional, personal and societal. Functional is evaluation of what the function of the outcome will be-to be compared to the intention. Personal refers to consequences for me as an individual (and other individuals involved in the process) —effort, danger and recognition. Societal refers to more overarching considerations, such as those related to environmental effects and the limited amount of primary and secondary resources available. Within societal we also include organisational considerations.

\section{Implications of this model of technological literacy}

Drawing on our model above, technological literacy is thus a quality of a process that originates in the relationship between individuals and a particular situation. In that way, technological literacy is not something that primarily resides with(in) an individual, but must be seen as relational between one individual (or several) and the technology as it manifests itself in the particular situation. Furthermore, a process that embodies technological literacy includes all the components of the enactment of potential that is indicated in our model. For example, it is required that there are elements of knowledge, personal engagement, and social engagement from which to build a potential and that they are enacted in such a way that they further the solution of the problem on which the process is focused. In the following sections we look at what our model says about technological literacy in the context of individuals on the one hand and society on the other.

Implications for technological literacy in the context of the individual

To be considered technologically literate, an individual needs to constitute a certain potential and have the possibilities to enact this potential (in relation to the situation). Learning that implies participating in a series of situations where aspects of knowledge come to the fore, motivations for personal engagement become clear, and framings of social engagement become manifested. Furthermore, the experience of enactment must become figural. In such a way, an individual can learn to reconstitute technological literacy 
in processes that have importance in his/her life. It is important to note that we are still considering technological literacy with the relational perspective discussed earlier. However, in this section we focus on how individuals moving from one situation to another consequently develop a 'history' of technological literacy based on different situations.

The context defines the role that an individual takes within a process. For example, say you are in the process of renovating your house. You have a project manager to ensure that the process is completed as per your requirements. As the owner, your level of technological 'literateness' is not relevant in the process-even though you may have the space to contribute-because you have employed a professional project manager. Thus, the role that you take is one of passive involvement. The moment you engage more actively in the process, perhaps as quality control, or perhaps just by discussing the progress with the craftsmen on a level which engages with the technology being enacted, both parties are now enacting a potential for technological literacy - and are thus, in this situation, considered technological literate. In particular, a discussion of this type would draw on evaluation as a key aspect of personal engagement, and you and the craftsman would have included each other in a participatory exchange. There may also possibly be scope for more active involvement on your side if, for example, you decide that you would like to complete a particular aspect yourself such as installing the wooden kitchen counter top. You would now take on the role of craftsman, and if the craftsman is present, s/he may engage you in a discussion on the details of what you are doing-you have reversed your roles in this part of the process.

This brings us to a key point in our argument. Roles that individuals can assume in a process that embodies technological literacy cannot be assumed to be fixed. Rather, they are something that are negotiated, through social engagement, where there is scope for this to take place-presupposing that the potential for enacting the process exists. Through this process, there is also the possibility for developing the various pillars of an individual's potential for technological literacy (see Fig. 1), and in that way preparing to take up other roles in similar situations.

Analysing a process must be undertaken with respect to several contexts at the same time-be they local contexts constituted in terms of spacial and temporal aspects, or otherwise as part of a greater scheme. An individual's enactment may adhere primarily to any of these levels, but is necessarily participating and shaping the process in all of them. A process that embodies technological literacy is characterised by bringing several of these levels to bear on each other. If this is not the case, quite disastrous results may emerge. A recent newspaper article (Engelbrektson 2007) told the story of a Swedish family who had bought a piece of land where they wanted to build a house. They consulted an architect who made a drawing of a house which fulfilled their requirements. As the next step they hired a carpenter to build the house for them, which he duly did. When the house was almost complete, a building inspector from the local municipality came for a standard inspection of the building. He decided to condemn the house as uninhabitable (and the owners were not allowed to enter the house) as it did not have proper supporting walls in place. Six months later the family, the carpenter, and the architect found themselves in court to decide with whom the blame lay - and who would have to pay to rectify the error. What happened here? It emerged that the drawing from the architect was not sufficient to build a structurally sound house. The carpenter, in turn, had simply followed the design specifications of the drawing - putting in windows in the context of putting in windows, building a wall in the context of building that particular wall—without considering the whole of the house (which was the intended outcome of the process in the greater scheme). The family did not realise that they had assumed the role of the top-level managers of the 
process; and that they had the overall responsibility for a successful outcome. Following our argument, we would characterize the three parties as not taking part in the same process - and lacking in terms of personal engagement - especially in terms of evaluation of consequences for the outcome. Furthermore, we would argue that there were elements of capability, content and skill missing.

Underlying our reasoning above is a recognition of the heterogeneity of individuals and situations. There are a multitude of roles to take, competencies to develop, and technological goals to pursue in our daily life. What we believe would flag an individual as technological literate is their display of a capability to bring knowledge and personal engagement to bear in the enactment in different roles and in so doing, allowing for negotiation of work-sharing, intention, problem, need, as well as roles with others. The complexity of an individual's life and different competencies does allow for a blending of roles from different aspects of life-that can have impact on technological processes in different ways. Developing your technological literacy thus means to develop the parts that give you best flexibility in the roles you assume in your life, and gives you the ability of being open to assuming different roles. Technological literacy does not mean that you do, choose to do, and are able to do everything in a particular situation.

\section{Implications for technological literacy in the context of society}

In addition to the implications discussed for the individual, we want to stress the importance of the societal perspective. In society, there are numerous technological processes going on which have shaped and are currently shaping the very structure of our lives. For example, many of the things we do to improve our quality of life includes the process of producing and using various technological artefacts. To manage the successful outcome of these processes, there are a multitude of experts of various kinds-defined, for example, by profession or position in society. Looking at the interaction between these groups, we can ask whether these processes can be characterized as embodying technological literacy. For example, we can ask whether the social engagement is open to negotiation around the roles (and responsibilities) taken by different kinds of experts. Or we can ask whether there is a mutual personal engagement in evaluation of the appropriateness of the process they are involved in. A particular aspect we wish to raise is the inherent power relationship between the persons involved and the consequences this can have for social engagement. In some cases, influence is matched by the level of potential and enactment, while in others, the most relevant potential may be excluded from the enactment through access barriers to social engagement, for example, specific communities of practice may not easily draw on knowledge from the outside. We suggest that an important aspect of technological literacy is to handle the impact of power relations on technological processes.

As an example, the role of the master craftsman, or expert, as the keeper of knowledge associated with these technological processes began to change with the emergence of the printing press. It was then possible for information to be more widely disseminated and for non-traditional 'technologists' to begin to develop an understanding of the field and move toward having the possibility to be technologically literate. Not surprisingly, it was around this time that patents emerged as a way of formalizing rights to ideas and processes as individuals engaged in protecting their rights in a society that was rapidly moving towards the sharing of knowledge (cf. Hansson 1996). Thus, in broadening the discussion from the collective of 'expert groups', it is important to consider how technological literacy manifests itself in society for 'the rest' of the population. It is common cause that most people find themselves in the role of a consumer of technology. The implication of this role is that 
their possibilities to engage in the process are very limited. Keirl (2006, p. 90) points to the importance of broadening the public's participation in technology from the application of technologies stage, to earlier stages in the life of technologies, for example the manifestation stage, where technological artefacts finalize their form and function. This would open up the possibility for interacting with that technology, and relate its form and function to an analysis of consequences, as well as ethical aspects of its very existence. We can summarise this as the importance of allowing democratic elements to structure technological literacy in society, which implies the reduction of barriers of entry into this social engagement around technological artefacts that populate and shape our lives.

Following on from the development of such social engagement is the establishment of technological literacy as a proto-democratic practice and 'a form of life' (Molander 2002, p. 363) concerning technology in society. The establishment of such a practice also opens the space for discussions and negotiations about what the purpose of technology and technological literacy (or life in the broader picture) is. This immediately points to ethical discussions on technology in our lives, for example, the good life as depicted by Borgmann (Borgmann 2006; Higgs et al. 2000), or, more broadly, discussions around technology and values in the philosophy of technology (cf. Hanks 2010).

\section{Concluding remarks}

It is clear that in the development of technological literacy, technology education plays an important role in preparing individuals to take their place in an ever increasingly technological society. However, we suggest that a pre-requisite for developing technological literacy is more than just a focus on technology education-primarily because this does not satisfactory develop the social engagement and enactment aspects of technological literacy. We illustrate this position using an example from our previous work (Collier-Reed 2008) where many of the school pupils interviewed could give a formal definition of technology and could for example describe the design process in some detail. However, when given the opportunity to interact with technological artefacts, the nature of which was within their scope, many were hesitant to interact with them at any level.

In the case of our model, the central argument concerns people negotiating about the purpose within a technological process, and giving each other space to engage that purpose, to potentially achieve a common goal. In a broad sense, the social engagement is built from a potential of individuals' knowledge in relation to the potentials of technological artefacts. This contrasts to several of the mainstream scholars in the field of philosophy of technology (see, for example, Mitcham 1994), who rather build their argument around the potential and purpose of technology and the technological artefact per se.

In this article we have identified the development of capability and personal engagement as two of the key issues that need to be strengthened in developing technological literacy in educational contexts. We would even argue that the content aspects of technology can, to a large extent, be further developed as a consequence of the sense of capability and personal engagement. The main route to this capability development is through interaction in a supportive participatory environment. We point to legitimate peripheral participation (Lave and Wenger 1991) as the vehicle through which social and personal engagement can be encouraged and evolve. This assumes that the more experienced persons involved in the process are open to mutual engagement amongst all those involved. That is, they take a responsibility to be inclusive in the process of supporting the 
novice's peripheral participation. For the more knowledgeable, this is an essential part of enacting technological literacy.

Even though we have argued the importance of recognizing the need for capability and personal engagement, and do not specifically put these experiences within a schooling environment, we still see a pressing need for general technology education to take up these challenges. We do not support the view of Devon and Ollis (2007) that the need for technology education programmes at schools has 'diminished'. Instead, we believe that schools should take up the challenge of developing the capacity of pupils to enact the knowledge that they currently develop, and to provide support for that enactment to take place outside school in contexts which matter in their lives. In line with many others, we also want to emphasize the importance of focusing not only on technological artefacts, but particularly also on the development of capability, in order to see the technological dependencies and the nature of technology in everyday situations.

Finally, at the societal level, we have highlighted the multi-disciplinary interactions that are possible between different kinds of experts and lay persons involved in various technological processes in specific contexts. It is not only general technology education that needs to support the framework for this interaction, but discipline professionals must develop the ability for mutual engagement in processes that involve people from other disciplines, as well as novices and lay persons.

Acknowledgements We acknowledge funding from Swedish Research Links (VR-SIDA-NRF) as well as the Swedish Research Council (VR-UVK). We would also like to thank the anonymous reviewer who made a significant contribution to the conceptualisation of the notion of personal and social engagement in our model.

Open Access This article is distributed under the terms of the Creative Commons Attribution Noncommercial License which permits any noncommercial use, distribution, and reproduction in any medium, provided the original author(s) and source are credited.

\section{References}

Barnett, M. (1995). Literacy, technology and 'technological literacy'. International Journal of Technology and Design Education, 5, 119-137.

Borgmann, A. (2006). Real American ethics: Taking responsibility for our country. Chicago: University of Chicago Press.

Collier-Reed, B. I. (2008). Pupils' experiences of technology: Exploring dimensions of technological literacy. Saarbrucken, Germany: VDM Verlag Dr. Mueller e.K.

Dakers, J. R. (2006). Defining technological literacy: Towards an epistemological framework. New York: Palgrave Macmillan.

de Vries, M. J. (2005). Teaching about technology: An introduction to the philosophy of technology for nonphilosophers. Dordrecht, New York: Springer.

de Vries, M. J. (2006). Technological knowledge and artefacts: An analytical view. In J. R. Dakers (Ed.), Defining technological literacy: Towards an epistemological framework (pp. 17-30). New York: Palgrave Macmillan.

Devon, R., \& Ollis, D. (2007). AC2007-1430: Technology literacy for the technologically literate. Paper presented at the 2007 ASEE annual conference.

Dugger W. E., Jr. (2008). The perspective of technology education. Paper presented at the Japanese international symposium on educational cooperation for industrial technology education.

Engelbrektson, L. (2007). Nya huset en mardröm (The new house was a nightmare). Göteborgs-Posten.

Feenberg, A. (2006). What is philosophy of technology? In J. R. Dakers (Ed.), Defining technological literacy: Towards an epistemological framework (pp. 5-16). New York: Palgrave Macmillan.

Frank, M. (2005). A systems approach for developing technological literacy. Journal of Technology Education, 17(1), 19-34. 
Gagel, C. W. (1997). Literacy and technology: Reflections and insights for technological literacy. Journal of Industrial Teacher Education, 34(3), 6-34.

Hanks, C. (Ed.). (2010). Technology and values: Essential readings. West Sussex: Wiley-Blackwell.

Hansson, S. (1996). Teknikhistoria: om tekniskt kunnande och dess betydelse för individ och samhälle [The history of technology: On technological knowledge and its importance for individuals and society] (2nd ed.). Lund: Studentlitteratur.

Hayden, M. A. (1989). What is technological literacy? Bulletin of Science Technology and Society, 9, 228-233.

Higgs, E., Light, A., \& Strong, D. (Eds.). (2000). Technology and the good life?. Chicago: University of Chicago Press.

International Technology Education Association. (2000/2002/2007). Standards for technological literacy. Content for the study of technology: International Technology Education Association.

Kahn, R., \& Kellner, D. (2005). Reconstructing technoliteracy: A multiple literacies approach. E-learning, 2(3), 238-251.

Keirl, S. (2006). Ethical technological literacy as democratic curriculum keystone. In J. R. Dakers (Ed.), Defining technological literacy: Towards an epistemological framework (pp. 81-102). New York: Palgrave Macmillan.

Lave, J., \& Wenger, E. (1991). Situated learning: Legitimate peripheral participation. Cambridge: Cambridge University Press.

Levande, J. S. (2003). A curricular and instructional challenge: Teaching and learning for technological literacy/capability. The Journal of Technology Studies, 29(2), 87-88.

Marton, F., \& Booth, S. (1997). Learning and awareness. New Jersey: Lawrence Erlbaum Associates.

Michael, M. (2006). How to understand mundane technology: New ways of thinking about human-technology relations. In J. R. Dakers (Ed.), Defining technological literacy: Towards an epistemological framework (pp. 49-63). New York: Palgrave Macmillan.

Mitcham, C. (1994). Thinking through technology: The path between engineering and philosophy. Chicago: University of Chicago Press.

Molander, B. (2002). Politics for learning or learning for politics? Studies in Philosophy and Education, 21, 361-376.

Pearson, G., Young, A. T., National Academy of Engineering, Committee on Technological Literacy, \& National Research Council (US). (2002). Technically speaking: Why all Americans need to know more about technology. Washington, DC: National Academy Press.

Roberts, D. A. (2007). Scientific literacy/science literacy. In S. K. Abell \& N. G. Lederman (Eds.), Handbook of research on science education (pp. 729-780). Mahwah, NJ: Lawrence Erlbaum Associates.

Rose, M. A. (2007). Perceptions of technological literacy among science, technology, engineering, and mathematics leaders. Journal of Technology Education, 19(1), 35-52.

Rose, L. C., \& Dugger, W. E., Jr. (2002). ITEA/Gallup poll reveals what Americans think about technology. A report of the survey conducted by the Gallup organization for the International technology education association. Technology Teacher, 61(6 insert), 1-8.

Rose, L. C., Gallup, A. M., Dugger, W. E., Jr, \& Starkweather, K. N. (2004). The second installment of the ITEA/Gallup poll and what it reveals as to how Americans think about technology. Technology Teacher, 64(1), 1.

Simpson, J. A., Weiner, E. S. C., \& Oxford University Press. (1989). The oxford english dictionary (2nd ed., Vol. VI). Oxford: Oxford University Press.

Steffens, H. (1986). Issues in the preparation of teachers for teaching robotics in schools. In J. Heywood \& P. Matthews (Eds.), Technology, society and the school curriculum. Manchester, England: Roundthorn Publishing.

Technology for All Americans Project, International Technology Education Association. (1996). Technology for all Americans: A rationale and structure for the study of technology. Reston, Va: International Technology Education Association.

Waetjen, W. B. (1993). Technological literacy reconsidered. Journal of Technology Education, 4(2), 5-10.

Wenger, E. (1998). Communities of practice: Learning, meaning, and identity. Cambridge, UK, New York, NY: Cambridge University Press.

Young, A. T., Cole, J. R., \& Denton, D. (2002). Improving technological Literacy: The first step is understanding what is meant by "technology". Then we must try to reach the broadest possible audience. Issues in Science and Technology, 18(4), 73-79. 